\title{
Destructive Effects of Distraction on Younger Generation
}

\author{
R. Mayildurai, S. Logeshkumar, A. Priyanka, A.S. Mythili
}

\begin{abstract}
Distraction is the process of deviating one's concentration from the desired task. It can be from both external as well as internal factors such as laziness, lack of attention, nervousness, addiction towards electronic gadgets, more passionate on social media etc. Various psychological studies illustrate that switching between responsibilities occurs among the mankind. Sometimes distraction is valuable for human to forgot or escape from their agony. But at the same time it creates destructive effect on younger generations. This study focuses on the various internal and external factors which distracts the younger generation especially students studying in the undergraduate courses. Once they deviate due to lack of attention, they involve themselves in hostile activities, develop unnatural behaviours which affects their carrier and sometimes makes it impossible for them to reach their ambitions. A quantitative method was used in gathering and analysing the data by distributing questionnaires to the students. The results obtained were analysed for different factors that cause stress among students.
\end{abstract}

Key word: distraction, destructive effect, carrier

\section{INTRODUCTION}

A distraction is anything that takes ones attention or focus from what he/she is supposed to be doing. The word distraction comes from the Latin words dis-"apart," and trahere-"drag." Distraction can have either positive or negative effects on humans. A distraction can also be a pleasant break. Positively speaking, distraction is an entertainment that provokes pleased interest and distracts you from worries and vexations. Negatively speaking, distraction may cause you to get deviated from the work which you are doing thereby causing negative effects. Such negative effects include deviation from your present goal, loss of interest in your family relationship etc... Every day, the negative impacts of distraction keep people from maintaining focus and productivity.[1] Distraction is now-adays common among college students. The problem of distraction can deviate them from their goal. Distraction may be due to both internal and external factors. Distractions among college students may be due to various factors such as laziness, social media, smartphones, family conditions, other psychological reasons and so on. In this modern world, the growth of technology has given a lot of useful products and services to mankind. But, recent studies

Revised Manuscript Received on August 14, 2019.

R. Mayildurai, Department of Science and Humanities, Kumaraguru College of Technology, Coimbatore. 641049. Tamilnadu, India.(E-mail: rmdurai79@gmail.com).Ph -+919842318875

S. Logeshkumar, Department of Electrical and Electronics Engineering, Kumaraguru College of Technology, Coimbatore, 641049. Tamilnadu, India.

A. Priyanka, Department of Management Studies, Kumaraguru College of Technology, Coimbatore, 641049. Tamilnadu, India.

A.S. Mythili, Department of Science and Humanities, Kumaraguru College of Technology, Coimbatore. 641049. Tamilnadu, India. have shown that technology like smartphone is a major distraction, affecting the success rates of the students who use it everyday in their classrooms. In modern days, it is difficult to maintain the concentration of college students at its maximum potential during the class time, as there are numerous distractions that negatively impact students' focus and prevent optimal learning. [2] Technological gadgets such as laptops and cell phones have invaded the classroom, raising considerable concerns about their effects on college students' attention in the classroom. Nowadays, Smartphones turn out to be a major part of our life due to its advanced features. [3] Mobile phones are one of the most common information access devices with almost $31 \%$ of the global population having access. [4] It is difficult to avoid such new technologies, while we all know the effect of mobile phone on our society and also on our environment. But excessive usage of smartphones impacts the learning capability of students. [5] Apart from Smartphones, there are various other factors like the environmental conditions of the students, their friends and family circle which distracts the students and deviates them from their goal. This study is an attempt to identify the major causes for distraction among younger generations and attempts to bring out the effective solutions for such problems.

\section{METHODOLOGY}

This study attempts to identify the causes of distraction on college students, in view of the purpose of this study, a questionnaire was structured carefully. Simple and easy words were used so that student respondents can easily understand as well as answer the questions. Possible answers were provided to enable the students to tick which ever answer they find suitable in terms of their response to the question. The questionnaire comprises of twenty main question and fifteen sub questions which are relate with main questions. The questionnaire was circulated among the college students in various district of Tamilnadu, India. More than three hundred responses were received from the students and the data was recorded. In this, responses were obtained from students involved in various fields such as Engineering, Sciences, Law, etc.

\section{RESULTS AND DISCUSSION}

Students aged between 18 and 21 years were the respondents of this survey. As the students are in the college level, it is the time for them to focus on their career. 
In order to have good career, it is important to have good health condition first. A good night's sleep is incredibly important for good health. Unfortunately, the modern life style is interfering with natural sleep patterns. It is evident that a person with improper wake up timing may have sleep deprivation.

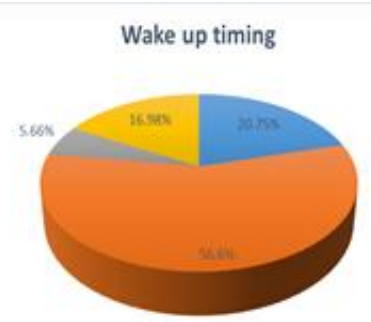

Figure 1: Graph showing wake up timing of students.

While sleep requirements vary slightly from person to person, most healthy adults need between 7 to 9 hours of sleep per night to function at their best. Children and teens need even more. From the survey we can found out almost $57 \%$ of the students woke up between 6 and 7 am. They might get almost the sufficient amount of sleep as required by an adult. But almost $17 \%$ of the students have improper wake up timing (Figure 1). Improper wake up timing affects the person both mentally and physically. Some of the effects of sleep deprivation include increased risk of disease, high blood pressure, weakened immune system, impaired creativity etc... Research finds that a person with improper sleep has less creativity, analytical and reasoning skills. Thus to maintain good physical and mental health conditions, it is important to have balanced sleep.

The student who wakes up early has more time in a day to do work. Most of the colleges starts by 8:30am (some colleges by 9:00am). So the student has to get up early so that he/she can get more time to do the work in a day. Almost $17 \%$ of the students have varied wake up time. This problem of varied wake up time reflects in their class attending time also.

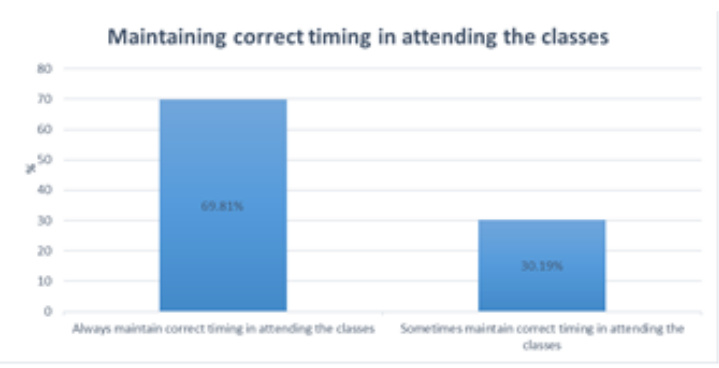

Figure 2: Graph showing the percentage of students regarding punctuality in attending the classes.

This causes distraction not only among the students but also in the classroom environment. $30 \%$ of the students fails to attend the classes in correct time at regular intervals (Figure 2). Students who wake up early have more time so that they can attend their classes on time.

Students with distracted mind cannot focus on any of their present work including studies. This situation motivates them to postpone their work. College students have to develop several skills so that they can find a good career. It is found that $7.5 \%$ of the college students usually postpone their work even when they have no other important work to do (Figure 3). That is they easily get addicted to Smartphones, Mobile and PC games, Social media such as facebook, twitter,etc...

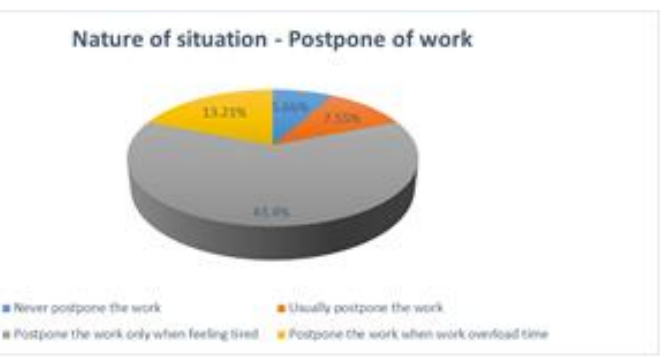

Figure 3: Graph showing the nature of situation when students postpone their work.

Addiction of this sort reduce their focus in their career path. Students should be aware of such things and try to make their professional life better.

Technological advancements have given a lot of things to us to make our life easier. We can save a lot of time by utilizing such technologies. But like a coin with two sides, this can led to a lot of distraction especially among students depending upon the usage.

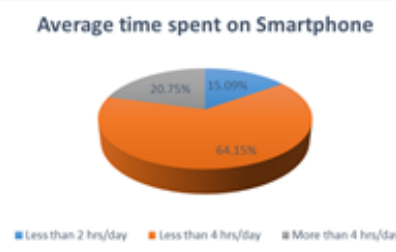

Figure 4: Graph showing average time spent by the students on smartphone.

Smartphone addiction is a common problem among younger minds now-a-days. Students get easily addicted to mobile games, social media, etc...It is to be noted that $20.75 \%$ of the students use their smartphones for more than $4 \mathrm{hrs} /$ day (Figure 4). Any technology should be used only for the constructive purpose and not for the destructive purpose.

As college students are young adults, they have their own personal life. They have to maintain the balance between various relationship such as family, friends, etc... 43.4\% of students sometimes feel that they are discouraged by their friends. $16.98 \%$ of the students feel that there is no one to motivate them when they feel discouraged (Figure 5). Such students may easily get exposed to mental stress. This problem may even distract them from their goal and may often leads them astray. So care should be taken to develop mental confidence among college students. Students should be mentally strong enough to face the problems that they face in their day-to-day life. 


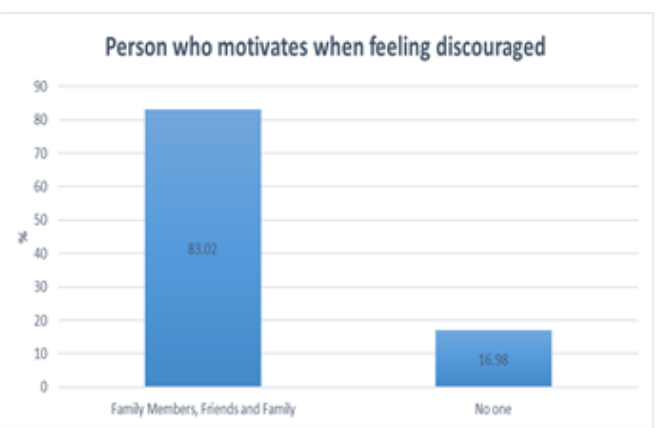

Figure 5: Graph showing the persons who motivate the students when they feel discouraged.

After finishing the high school, majority of the students have no clear idea about their career. They are in a confused situation to choose the area that best suits them. Some of them get advice from their seniors, family members, relatives, etc... Most of the students were forced by others to choose their current field in which they are not interested in. Around $42 \%$ of the students choose their current field either because of family advice or some forms of external social influence (Figure 6).

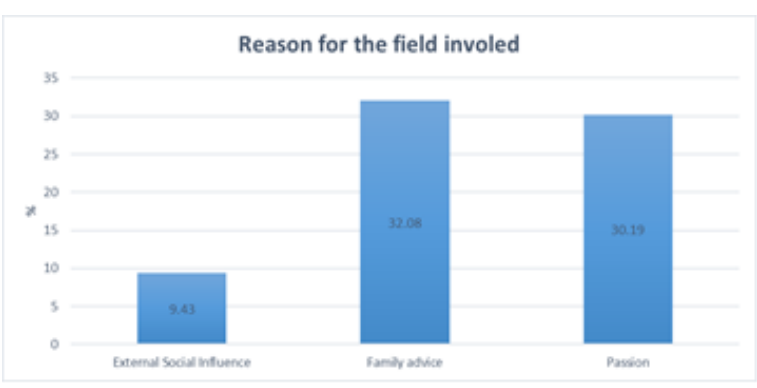

Figure 6: Graph showing the cause which made students to choose their current field.

Only $30 \%$ of the students choose their current field because of their passion. $71.7 \%$ of the students are satisfied with their current field. About $28.3 \%$ of the students are not satisfied with their current field. Lack of interest in the field may create mental disturbances. So students should be guided in such a way that they can choose their career on their own.

\section{CONCLUSION}

From the above discussion it is inferred that there are various causes which cause distraction among younger minds. These causes include improper timing, lack of persons to guide and support, improper usage of technological advancements external social influence etc... Some of these problems even affect physical health of the students. Sometimes distraction is helpful to overcome stress. Everyone has a potential to achieve their goals. But we should focus on our goals with determination. "Problems are common for everyone. But attitude makes the difference."

\section{REFERENCES}

1. Leung, Kimberly. "The Effect of Distractions on Task Performance and Enjoyment as Moderated by Regulatory Fit." (2015).
2. Attia, Najya A., Lubna Baig, Yousef I. Marzouk, and Anwar Khan. "The potential effect of technology and distractions on undergraduate students' concentration." Pakistan journal of medical sciences 33, no. 4 (2017): 860

3. Gowthami, S., and S. V. K. Kumar. "Impact of smartphone: A pilot study on positive and negative effects." International Journal of Scientific Engineering and Applied Science (IJSEAS) 2, no. 3 (2016): 473-478.

4. Mendoza, Jessica S., Benjamin C. Pody, Seungyeon Lee, Minsung Kim, and Ian M. McDonough. "The effect of cellphones on attention and learning: The influences of time, distraction, and nomophobia." Computers in Human Behavior86 (2018): 52-60.

5. Chakraborty, Sayan. "Mobile phone usage patterns amongst university students: A comparative study between India and USA." (2006) 